\title{
KINETIC MECHANISM FOR LOW-PRESSURE OXYGEN/METHANE IGNITION AND COMBUSTION
}

\author{
N. A. Slavinskaya ${ }^{1}$, M. Wiegand ${ }^{1}$, J. H. Starcke ${ }^{1}$, \\ U. Riedel ${ }^{1}$, O. J. Haidn ${ }^{2}$, and D. Suslov ${ }^{2}$ \\ ${ }^{1}$ Institute of Combustion Technology \\ German Aerospace Center (DLR) \\ 38-40 Pfaffenwaldring, Stuttgart 70569, Germany \\ ${ }^{2}$ Institute of Space Propulsion \\ German Aerospace Center (DLR) \\ Langer Grund, Lampoldshausen 74239, Germany
}

\begin{abstract}
It is known that during a launch of a rocket, the interaction of the exhaust gases of rocket engines with the atmosphere causes a local depletion of the ozone layer. In order to study these chemical processes in detail, a chemical reaction mechanism of the methane oxidation appropriate for high- and low-pressure conditions and a chemical reactor network to reproduce operating conditions in rocket engines and in the environment have been developed. An earlier developed detailed chemical kinetic model for the high-pressure $\mathrm{CH}_{4} / \mathrm{O}_{2}$ combustion has been improved for the low pressure and low temperature methane combustion and augmented with a submodel for NOx formation. The main model improvements are related to the pressure depending reactions. The model has been validated for operating conditions of $0.02<p<100 \mathrm{~atm}$, $300<T<1800 \mathrm{~K}$ and $0.5<\phi<3.0$. The network of chemical reactors available in CHEMICAL WORKBENCH software has been successfully developed to simulate chemical processes in the convergent divergent rocket nozzle and in the exhaust-jet. Simulations performed have shown that the exhaust gases of a methane/oxygen propelled liquid rocket engine contain high amounts of active radicals, which can influence the formation of nitrogen compounds and consume ozone in the atmosphere.
\end{abstract}

\section{INTRODUCTION}

In recent years, the propellant combination $\mathrm{LOx} / \mathrm{CH}_{4}$ has attracted considerable attention in the USA, Europe, and Japan as a perspective combination for 
attitude control, the upper stage, or booster engines. In addition to these more traditional rocket engine applications, this fuel/oxidizer pair is also of interest for exploration missions [1-4]. For booster applications, this propellant combination has some system advantages compared to both $\mathrm{LOx} /$ kerosene and to $\mathrm{LOx} / \mathrm{LH}_{2}$. For the upper stage, $\mathrm{LOx} / \mathrm{CH}_{4}$ has still a $10 \%$ performance edge towards kerosene but a penalty which exceeds $30 \%$ towards hydrogen. The picture may change in case of reignition requirements when the interpropellant heat transfer has to be managed with severe consequences on boil-off or weight of insulation which will reduce the difference in performance significantly. In any case, the application of this propellant pair enables, at least for purging purposes, a replacement of the costly helium by cheap nitrogen which is a nonnegligible system advantage. Furthermore, the choice of one propellant pair for every propulsive stage offers the advantage of simplicity and helps to reduce the development cost due to less diverse boundary conditions.

In addition to the necessary system analysis studies which would identify favorable missions for this propellant combination, it is absolutely mandatory to increase the knowledge base about the detailed chemical kinetics which determine the ignition and combustion behaviour of this propellant combination for low pressure conditions.

In connection with these growing activities, more detailed investigations of the interaction of the rocket plumes, and more specifically, the exhaust gases and particles of the propellants interacting with the atmosphere will be necessary. That could allow for precise answers about the environmental impact of the foreseen large number of launches, which exceeds by far the current launch rate of about 40 launches per year.

The requirement to accurately predict the combustion performance and the heat load to combustion chamber walls of hydrocarbon-operated engines necessitates numerical tools with reliable chemical kinetic schemes. The hierarchical structure of hydrocarbon oxidation reactions makes the methane chemistry the principal reaction scheme for any hydrocarbon. Besides the interest in methane for rocket engine applications mentioned previously, this propellant being a renewable biofuel has seen rising interest for both economic and ecological reasons. This strong interest in methane has led to kinetic studies that highlight the important features of the $\mathrm{CH}_{4}$ combustion. In Table 1, several successful studies were collected together with the validation experimental data.

The mechanisms described in Table 1 are validated mostly for a higher pressure, i. e., gas turbine operating conditions. Therefore, the direct application of these mechanisms for the low-pressure operating conditions in rocket engines is not reasonable and can lead to interesting results.

In the last column of Table 1, the mechanism validations for nitrogen chemistry are presented. Generally, the main features of this chemistry are well known [8] and will be not described here. 
Table 1 Methane kinetic mechanisms and their validation data base

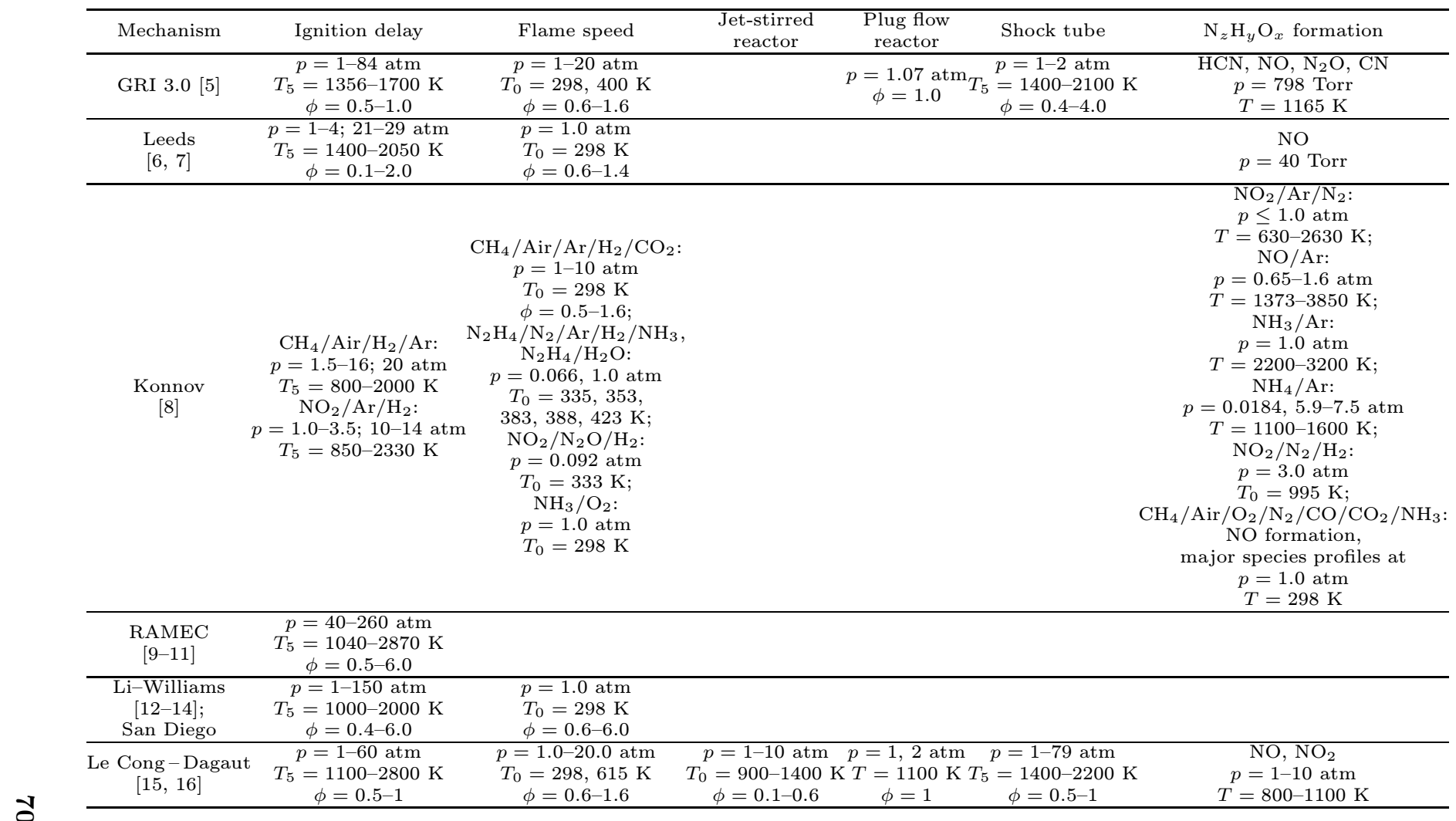


The purpose of this network is to create an efficient tool for simulating the chemical reactions in a converging-diverging nozzle, reproducing the temperature and pressure distribution in a rocket engine associated with the propulsion and in an exhaust jet. Such simulations allow predicting the possible chemical content of the hot exhaust at the nozzle exit and further modeling of the possible chemical interaction of the exhaust jet with the atmosphere.

To realize that, the extension of the earlier elaborated general kinetic scheme for $\mathrm{C}_{0}-\mathrm{C}_{1}$ combustion [17-19] to $(i)$ low-pressure methane oxidation and (ii) NOx formation has been performed. The kinetic mechanism has a strong hierarchical structure and is developed as a continual data base of chemical kinetic data for hydrocarbons. A previously developed $\mathrm{C}_{1}$ submechanism to describe atmospheric and high pressure (up to $60 \mathrm{~atm}$ ) $\mathrm{CH}_{4} / \mathrm{O}_{2}$ combustion [17] has been updated. The core $\mathrm{C}_{0}-\mathrm{C}_{1}$ submodel has been upgraded to model the low pressure and low temperature $\mathrm{CH}_{4} / \mathrm{O}_{2}$ combustion with $\mathrm{NOx}$ formation under operating conditions $0.02<p<1.0 \mathrm{~atm}, 900<T<1800 \mathrm{~K}$ and $0.5<\phi<3.0$.

The rocket plumes impact on the atmosphere has been simulated for two different altitudes, 16 (ambient pressure $0.1 \mathrm{~atm}$ ) and $31 \mathrm{~km}$ (ambient pressure $0.01 \mathrm{~atm})$. The effects of the pressure and temperature on the fundamental combustion properties and on the $\mathrm{CO}_{2}$ and $\mathrm{NOx}$ formation are discussed.

\section{CHEMICAL KINETIC MODEL}

The $\mathrm{C}_{0}-\mathrm{C}_{2}$ reaction submechanism presented in [17-19] is based on the $\mathrm{H} / \mathrm{O}$, $\mathrm{C}_{1}$, and $\mathrm{C}_{2}$ chemistry of the Leeds methane oxidation reaction scheme (see Table 1). The Leeds model $[6,7]$ has been selected as the base chemistry for the mechanism since it was developed mostly on the basis of "first principals," i. e., with a minimal set of fitted kinetic data. The mechanism update relates mostly to $\mathrm{H}_{2} / \mathrm{CO}$ and NOx submechanisms and is based on new advances in $\mathrm{H}_{2} / \mathrm{CO}$ chemistry.

Three new reactions have been added to the model:

$$
\begin{aligned}
\mathrm{HO}_{2}+\mathrm{HO}_{2} & \leftrightarrow \mathrm{H}_{2} \mathrm{O}_{2}+\mathrm{O}_{2} ; \\
\mathrm{O}+\mathrm{OH}+M & \leftrightarrow \mathrm{HO}_{2}+M ; \\
\mathrm{H}_{2}+\mathrm{O}_{2} & \leftrightarrow \mathrm{OH}+\mathrm{OH}
\end{aligned}
$$

with rate coefficients taken from $[20,21]$.

For the set of reactions:

$$
\begin{aligned}
2 \mathrm{H}+\mathrm{Ar} / \mathrm{N}_{2} / \mathrm{H}_{2} / \mathrm{H}_{2} \mathrm{O} / \mathrm{H} & \leftrightarrow \mathrm{H}_{2}+\mathrm{Ar} / \mathrm{N}_{2} / \mathrm{H}_{2} / \mathrm{H}_{2} \mathrm{O} / \mathrm{H} ; \\
\mathrm{OH}+\mathrm{H}_{2} & \leftrightarrow \mathrm{H}_{2} \mathrm{O}+\mathrm{H} ; \\
\mathrm{H}+\mathrm{O}_{2}\left(+M / \mathrm{Ar} / \mathrm{O}_{2} / \mathrm{H}_{2} \mathrm{O}\right) & \leftrightarrow \mathrm{HO}_{2}\left(+M / \mathrm{Ar} / \mathrm{O}_{2} / \mathrm{H}_{2} \mathrm{O}\right) ;
\end{aligned}
$$




$$
\begin{aligned}
& \mathrm{H}+\mathrm{HO}_{2} \leftrightarrow \mathrm{H}_{2}+\mathrm{O}_{2} \\
& \mathrm{H}+\mathrm{HO}_{2} \leftrightarrow 2 \mathrm{OH},
\end{aligned}
$$

rate coefficients have been updated. For reaction (1), a value based on the recommendation in [22] has been applied. For reaction (2), rate coefficients obtained from ab initio data presented in [23] have been adopted. A review of data in the literature for reaction (3) resulted in the replacement of rate coefficients used in the Leeds mechanism [6,7] with recommendations provided in [24]. Values of reaction rates for (4) and (5) from [25] have been modified within the range of their stated uncertainty: increased and decreased, respectively, by the factor of 0.3 . For reaction

$$
\mathrm{CO}+\mathrm{HO}_{2} \leftrightarrow \mathrm{CO}_{2}+\mathrm{OH}
$$

the recently obtained value of the rate coefficient with $a b$ initio study and master equation modeling [26] has been adopted with the factor of 0.5 . The reaction rate for one of the most important reactions for a laminar flame

$$
\mathrm{CO}+\mathrm{OH} \leftrightarrow \mathrm{CO}_{2}+\mathrm{H}
$$

has been changed to values from an experimental work [27]. The reaction rate of reaction

$$
\mathrm{H}+\mathrm{HCO} \leftrightarrow \mathrm{CO}+\mathrm{H}_{2}
$$

from [25] has been modified with factor of 1.2 .

\section{NOx Formation Pathways}

Generally, nitrogen chemistry is well investigated and its description can be found elsewhere $[5,8,15,16]$. The $\mathrm{N}_{2}$ submechanism in the present scheme has been adopted from Konnov's mechanism [8]. This choice has been made basing on the comparison of nitrogen reaction schemes richly proposed in the literature. The Konnov mechanism includes different reaction paths: Zel'dovich's reactions (thermal NOx formation); reactions of $\mathrm{N}_{2} \mathrm{O}$ formation; and the formation of prompt $\mathrm{NOx}, \mathrm{NNH}$, and fuel (from $\mathrm{NH}_{3}$ and $\mathrm{HCN}$ ) $\mathrm{NOx}$.

\section{MODEL VALIDATION}

All computed data for $\mathrm{CH}_{4}$ and $\mathrm{CO} / \mathrm{H}_{2}$ systems on ignition delay times, concentration profiles, and laminar flame speeds have been obtained by means of the SENKIN and PREMIX program from the CHEMKIN II package [28]. The sharp temperature rise was taken as the ignition criterion. Computer simulations of laminar premixed flames were performed with thermal diffusion, for the assumption of a free flame. Care was taken in the computations to reach a final 
Table 2 Experimental data base for low-pressure $\mathrm{CH}_{4}$ combustion

\begin{tabular}{|c|c|c|c|c|c|c|}
\hline No. & Pressure & Composition & $\begin{array}{c}\text { Experimental } \\
\text { data }\end{array}$ & $\phi$ & $T_{0}, \mathrm{~K}$ & Reference \\
\hline 1 & $0.5 \mathrm{~atm}$ & $\mathrm{CH}_{4} /$ air & $\begin{array}{c}\text { Laminar } \\
\text { flame speed }\end{array}$ & $0.5-1.5$ & 300 & {$[29]$} \\
\hline 2 & $1.76-2.40 \mathrm{~atm}$ & $\mathrm{CH}_{4} / \mathrm{O}_{2} / \mathrm{Ar}$ & $\begin{array}{c}\text { Ignition } \\
\text { delay time }\end{array}$ & $1-2$ & $1500-1800$ & {$[30]$} \\
\hline 3 & $0.7-0.9 \mathrm{~atm}$ & $\mathrm{CH}_{4} / \mathrm{O}_{2} / \mathrm{Ar}$ & $\begin{array}{c}\text { Ignition } \\
\text { delay time }\end{array}$ & 1 & $1700-2200$ & {$[31]$} \\
\hline 4 & $0.54-1.0 \mathrm{~atm}$ & $\mathrm{CH}_{4} / \mathrm{H}_{2} / \mathrm{Air}$ & $\begin{array}{c}\text { Ignition } \\
\text { delay time }\end{array}$ & 0.5 & $1130-2000$ & {$[32]$} \\
\hline 5 & 25-30 Torr & $\mathrm{CH}_{4} / \mathrm{O}_{2} / \mathrm{Ar}$ & $\begin{array}{l}\text { Concentration } \\
\text { profiles }\end{array}$ & $0.81-1.28$ & $400-2000$ & {$[33]$} \\
\hline 6 & 40 Torr & $\mathrm{CH}_{4} / \mathrm{O}_{2} / \mathrm{Ar}$ & $\begin{array}{l}\text { Concentration } \\
\text { profiles }\end{array}$ & 1 & $450-1800$ & {$[34]$} \\
\hline 7 & $0.16 \mathrm{~atm}$ & $\mathrm{CH}_{4} /$ air & $\begin{array}{c}\text { Laminar } \\
\text { flame speed }\end{array}$ & $0.8-1.3$ & 300 & {$[35]$} \\
\hline 8 & $1 \mathrm{~atm}$ & $\mathrm{CH}_{4} /$ air & $\begin{array}{c}\mathrm{NO} \\
\text { concentration } \\
\text { profile }\end{array}$ & 0.5 & $300-1800$ & {$[36]$} \\
\hline 9 & $1 \mathrm{~atm}$ & $\mathrm{CH}_{4} / \mathrm{O}_{2} / \mathrm{NO} / \mathrm{N}_{2}$ & $\begin{array}{c}\mathrm{CO}, \mathrm{CO}_{2}, \\
\mathrm{NO}, \mathrm{NO}_{2} \\
\text { concentration } \\
\text { profile } \\
\end{array}$ & 0.1 & $800-1150$ & {$[37]$} \\
\hline 10 & $0.6-18$ atm & $\begin{array}{l}20 \% \mathrm{CO} / 80 \% \mathrm{H}_{2} \\
40 \% \mathrm{CO} / 60 \% \mathrm{H}_{2} \\
80 \% \mathrm{CO} / 20 \% \mathrm{H}_{2} \\
90 \% \mathrm{CO} / 10 \% \mathrm{H}_{2}\end{array}$ & $\begin{array}{l}\text { Ignition } \\
\text { delay time }\end{array}$ & 0.5 & $890-1285$ & {$[38]$} \\
\hline 11 & $1.15-1.4 \mathrm{~atm}$ & $\begin{array}{l}80 \% \mathrm{CO} / 20 \% \mathrm{H}_{2} \\
90 \% \mathrm{CO} / 10 \% \mathrm{H}_{2} \\
\end{array}$ & $\begin{array}{c}\text { Ignition } \\
\text { delay time }\end{array}$ & $\begin{array}{c}0.5,0.9 \\
1.0 \\
\end{array}$ & $909-965$ & {$[39]$} \\
\hline 12 & $1 \mathrm{~atm}$ & $\begin{array}{l}50 \% \mathrm{CO} / 50 \% \mathrm{H}_{2} \\
95 \% \mathrm{CO} / 5 \% \mathrm{H}_{2}\end{array}$ & $\begin{array}{c}\text { Laminar } \\
\text { flame speed }\end{array}$ & $0.5-6$ & 300 & {$[40-42]$} \\
\hline
\end{tabular}

solution (no evolution of laminar flame speed when the number of mesh points is increased); typically, around 500 mesh points were computed.

The present mechanism has been validated applying the experimental data base collected in Table 2. Unfortunately, there is only a very limited set of measured data for ignition delays, laminar flame speeds and concentration profiles obtained for low pressure conditions. Therefore, ignition delay data measured at 1.76-2.40 atm behind a shock wave in [34] and NOx concentration profiles obtained at $1 \mathrm{~atm}$ have been included in the validation data base.

Effects of the positive flame stretch on the laminar burning velocities of methane/air flames were studied experimentally in [29] for $\phi=0.60-1.35$ and 


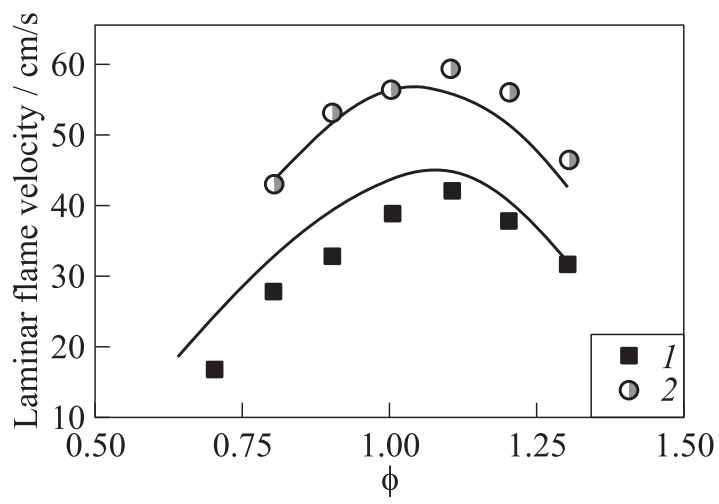

Figure 1 Laminar flame speed vs. equivalence ratio $(\phi)$ of $\mathrm{CH}_{4} /$ air flames for $T_{0}$ $=298 \mathrm{~K}$ and $p=0.5(1,[29])$ and $0.16 \mathrm{~atm}(2,[35])$. Signs refer to experimental data $[29,35]$ and curves to simulations with current mechanism

pressures of 0.5-4.0 atm, at ambient temperatures. In [35], experiments for methane-air flames at 125 Torr from a Hencken burner have been performed to show their unique structure for detailed flame studies. Flames were stabilized at a significant height above the burner surface with the properties being steady, laminar, nearly one-dimensional, minimally curved, weakly stretched, and near adiabatic. The comparisons of low-pressure flame speed simulations with experimental data $[29,35]$ are presented in Fig. 1 . The model describes the experimental data generally satisfactorily. Trends of the experimental results [29] and simulations are similar, but for lean mixtures slight overpredictions occur. Calculations of data [35] show the trend that slightly deviates from the experimental results at the flame speed peak. The calculated flame speeds are in excellent agreement with the data [35] for lean mixtures and lower than the data for $\phi>1.0$. Lastly, if a 10 percent uncertainty is estimated and applied to the results of $[29,35]$, the flame speed simulations appear to be in reasonable agreement with experimental data.

Figure 2 compares the predicted ignition delay times to those measured in [30] for stoichiometric and fuel-rich mixtures with equivalence ratios between 1 and 2 and pressures ranging from 1.76 to $2.40 \mathrm{~atm}$. The simulation results agree well with the data.

Ignition delay times for pressures between 0.54 and $1.0 \mathrm{~atm}$ were measured in $[31,32]$ behind reflected shock waves. Ignition was deduced from end wall pressure measurements and $\mathrm{CH}^{*}$ chemiluminescence [32] and from measurements combining $\mathrm{OH}^{*}$ and $\mathrm{CH}^{*}$ chemiluminescence [31]. Comparison with these ignition delay data (Fig. 3) is reasonably good. The presented models slightly overpredict the data $[31,32]$ for temperatures higher than $1800 \mathrm{~K}$. 


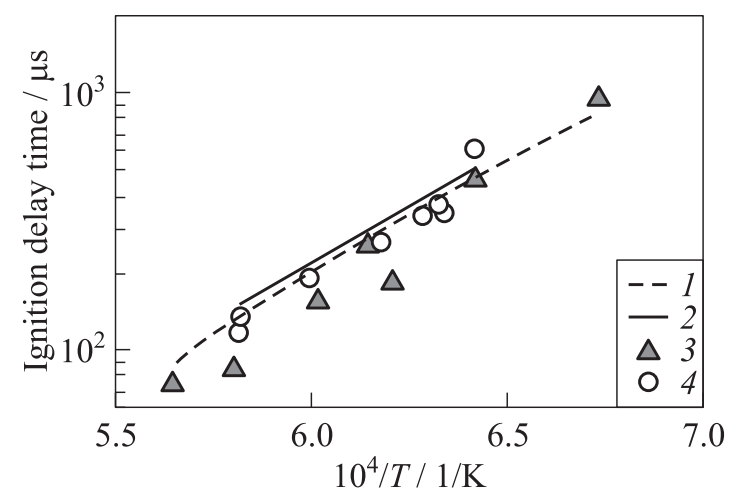

Figure 2 Comparison of modeled with current mechanisms ignition delays times of $\mathrm{CH}_{4} / \mathrm{O}_{2} / \mathrm{Ar}$ mixtures (curves: $1-2$ bar and $2-1.8$ bar) with experimental data [30] (signs): $3-p=1.85-2.40$ bar and $4-p=1.76-1.83$ bar

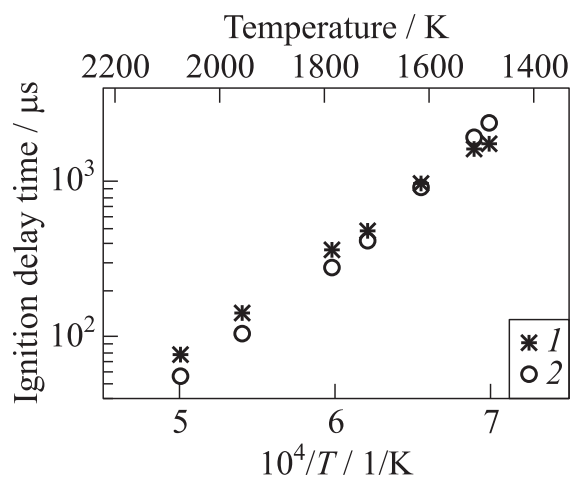

(a)

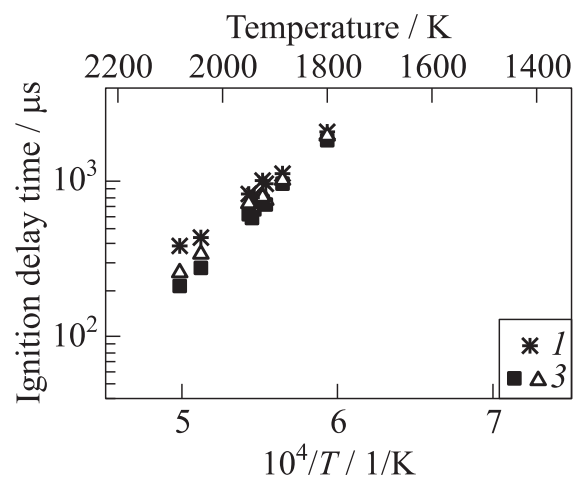

(b)

Figure 3 Comparison of modeled ignition delays time (1) of $\mathrm{CH}_{4} / \mathrm{O}_{2} / \mathrm{N}_{2}(p$ $=0.54-0.92 \mathrm{~atm}$ and $\phi=0.36)(a)$ and $\mathrm{CH}_{4} / \mathrm{O}_{2} / \mathrm{Ar}(p=0.8-1.0 \mathrm{~atm}$ and $\phi=1.0)$ mixtures $(b)$ with experimental data: $2-[32]$ and $3-[31]$

To complete the low pressure methane oxidation data set as much as possible, the $\mathrm{CH}$ and $\mathrm{OH}$ concentration profiles have been simulated and compared with those measured in [33] for extremely low pressure conditions: 25 Torr. The $\mathrm{CH}$ and $\mathrm{OH}$ concentration profiles have been measured in rich and lean premixed laminar methane flames, using laser-induced fluorescence calibrated with a Rayleigh scattering technique for LIF calibration.

Simulations of $\mathrm{CH}$ and $\mathrm{OH}$ radical concentrations measured in laminar premixed flames [33] are shown in Fig. 4. Although the data [33] have some uncer- 


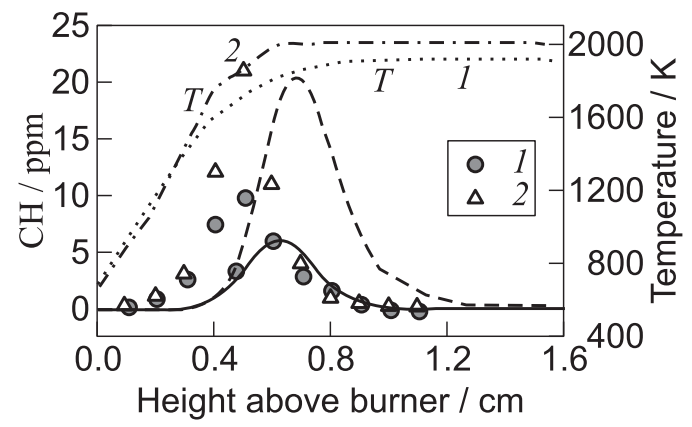

(a)

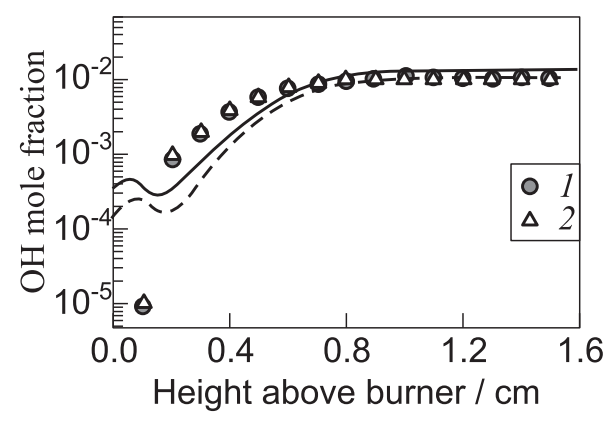

(b)

Figure 4 Comparison of modeled with current mechanisms $\mathrm{CH}(a)$ and $\mathrm{OH}(b)$ concentration profiles (curves) with measured $\mathrm{CH}_{4} / \mathrm{O}_{2} / \mathrm{N}_{2}$ laminar premixed flame data [33] (signs); $p=25$ Torr, and $\phi=1.07$ (1) and 1.28 (2)

tainties in the experimental conditions, it was important for this study to model these measurements, because $\mathrm{CH}$ and $\mathrm{OH}$ radicals are mostly used as indicators for ignition process development. As Fig. 4 shows, the proposed model reproduces satisfactory the $\mathrm{CH}$ and $\mathrm{OH}$ concentration changes. The shifts along the flame length may follow from experimental errors.

Experimental mole fraction profiles of stable and reactive species have been obtained in [34] by coupling the molecular-beam/mass spectrometry (MB/MS) with the gas chromatography/mass spectrometry (GC/MS) analyses. The flames have been stabilized on a flat flame burner at a very low pressure (40 Torr). Temperature profiles were measured with a coated thermocouple. The work provides a detailed experimental data set on the nature and concentrations of the stable and reactive species produced by oxidation of various representative natural gas mixtures.

In Figs. 5-7, the simulated and experimental concentration profiles of the reactants, stable intermediates, reactive radicals and final products in a laminar 


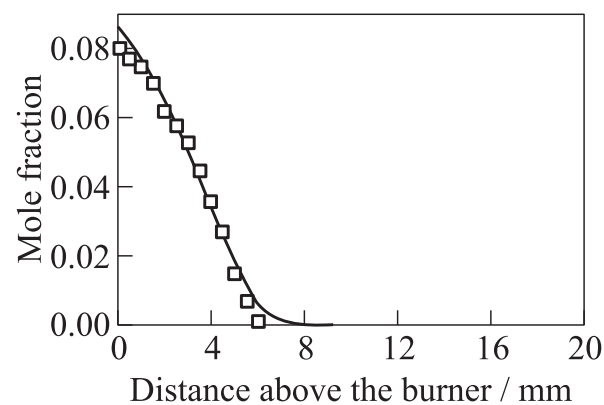

(a)

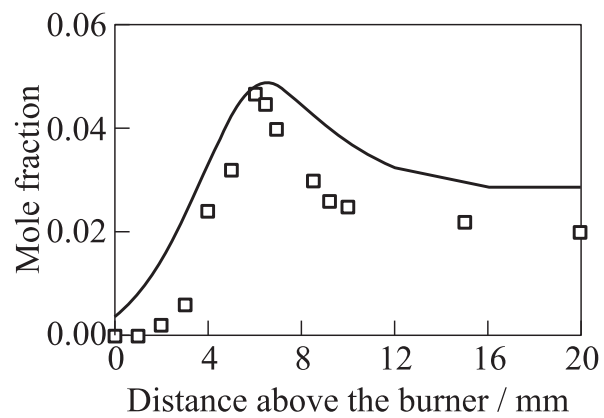

(c)

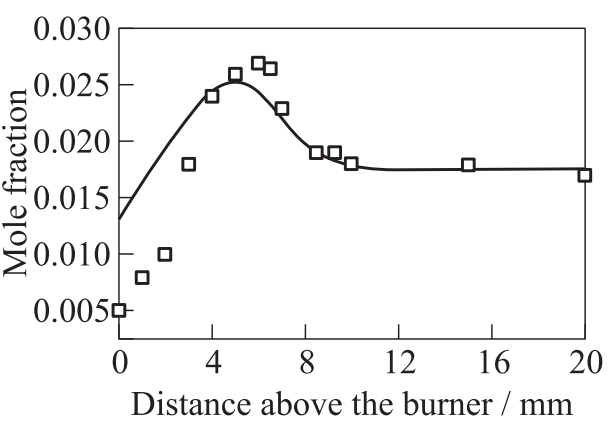

(b)

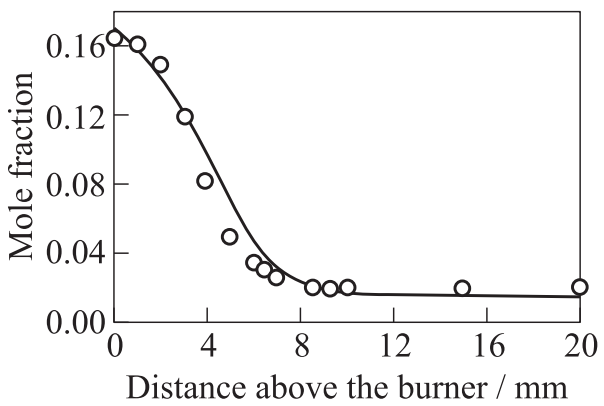

(d)

Figure 5 Comparison of modeled with current mechanisms (curves) $\mathrm{CH}_{4}(a), \mathrm{H}_{2}(b)$, $\mathrm{CO}(c)$, and $\mathrm{O}_{2}(d)$ concentration profiles with measured (signs) $\mathrm{CH}_{4} / \mathrm{O}_{2} / \mathrm{Ar}$ laminar premixed flame data [34], $p=0.05 \mathrm{~atm}$, and $\phi=1.05$

stoichiometric premixed $\mathrm{CH}_{4} / \mathrm{O}_{2} /$ Ar flame [34] are demonstrated. As can be seen from these figures, the model represents the data for the methane oxidation fairly well. The present modeling is in excellent agreement with the measurements for stable molecules and CO (see Figs. 5 and 6) and in reasonable agreement with data for radicals (see Fig. 7). The model underpredicts concentrations of $\mathrm{C}_{2} \mathrm{H}_{6}$ and $\mathrm{CH}_{2} \mathrm{O}$ (see Fig. $6 d$ ). Measured values for $\mathrm{OH}$ and $\mathrm{H}$ radicals are slightly underpredicted (see Figs. $7 a$ and $7 b$ ), whereas the discrepancy (an underprediction) between simulations and experimental data for $\mathrm{CH}_{3}$ and $\mathrm{HCO}$ radicals is by the factor of 2 .

Finally, one can conclude that the proposed simulation results obtained with the chemical kinetic scheme demonstrate an overall good agreement with experimental data measured at low-pressure conditions in different kinetic reactors using different techniques. A reasonable progress has been made in the extension of the core $\mathrm{C}_{1}$ submechanism to describe a low-pressure methane oxidation. 


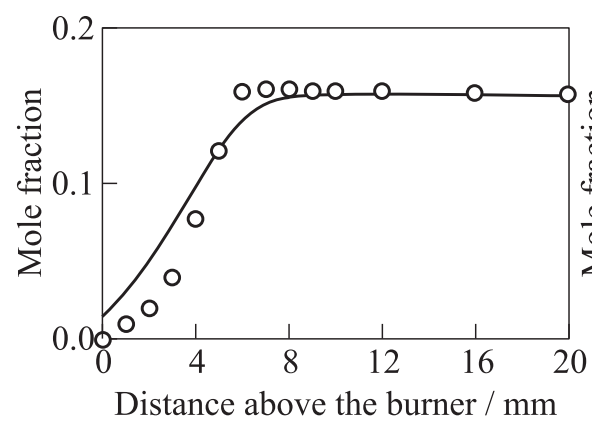

(a)

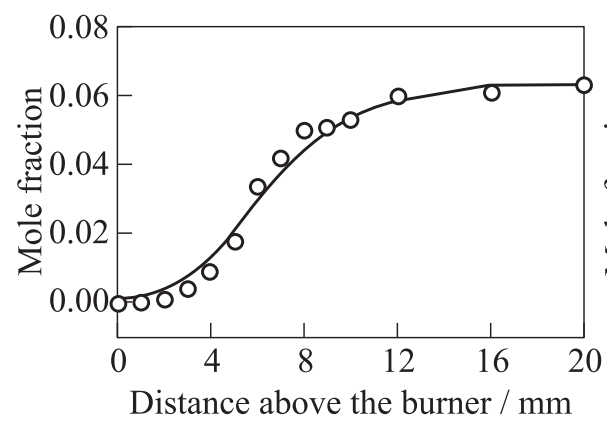

(c)

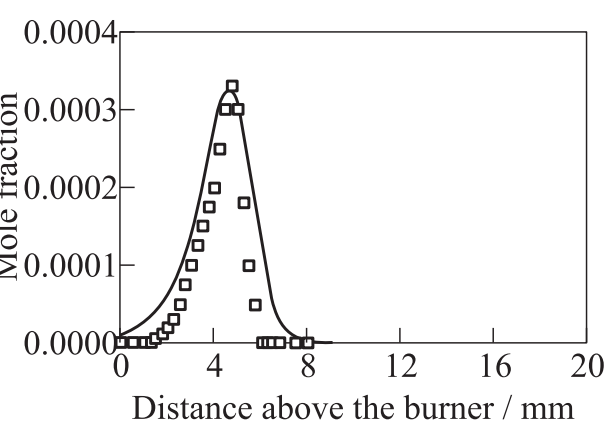

(b)

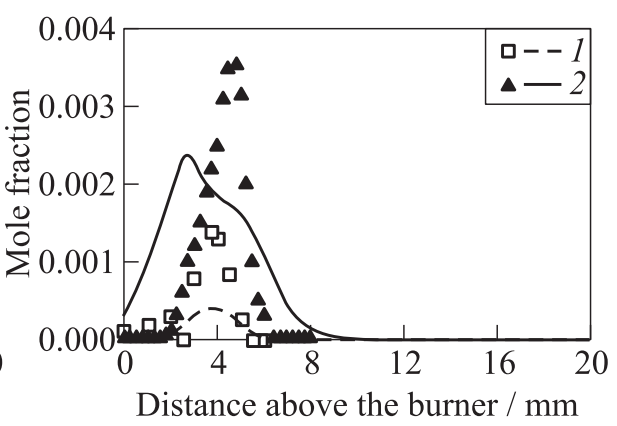

(d)

Figure 6 Comparison of modeled with current mechanisms (curves) $\mathrm{H}_{2} \mathrm{O}(a)$, $\mathrm{C}_{2} \mathrm{H}_{4}(b), \mathrm{CO}_{2}(c)$, and $\mathrm{C}_{2} \mathrm{H}_{6}(1)$ and $\mathrm{CH}_{2} \mathrm{O}(2)(d)$ concentration profiles and measured (signs) $\mathrm{CH}_{4} / \mathrm{O}_{2} / \mathrm{Ar}$ laminar premixed flame data [34]; $p=0.05 \mathrm{~atm}$ and $\phi=1.05$

Although it is not possible to present the analyses of the mechanism for all of the validation cases, the analyses for selected conditions were performed to get a sample of the characteristics of the mechanism and to compare its details for the low- and the high-pressure combustion.

The model facilities to reproduce $\mathrm{CO} / \mathrm{H}_{2}$ chemistry are demonstrated in Figs. 8-10 for two experimental sets of ignition delay times and laminar flame speeds. Laminar flame speed at atmospheric pressure for different mixtures of $\mathrm{CO}$ and $\mathrm{H}_{2}$ are reproduced perfectly by the model (see Fig. 8).

Although the model represents well the ignition delay data [38, 39], there is some disagreement between the measured and the calculated data: the model tends to overpredict some of the experimental data at temperatures below approximately $950 \mathrm{~K}$ (see Figs. 9 and 10).

At temperatures lower than about $1050 \mathrm{~K}$, the inhomogeneous ignition of high-energy-density syngas-oxygen mixtures takes place: perturbations by the 


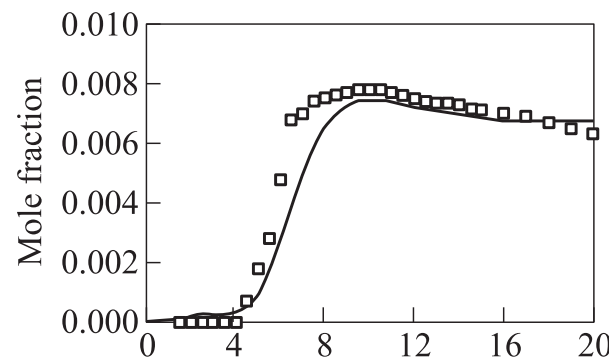

Distance above the burner / $\mathrm{mm}$

(a)

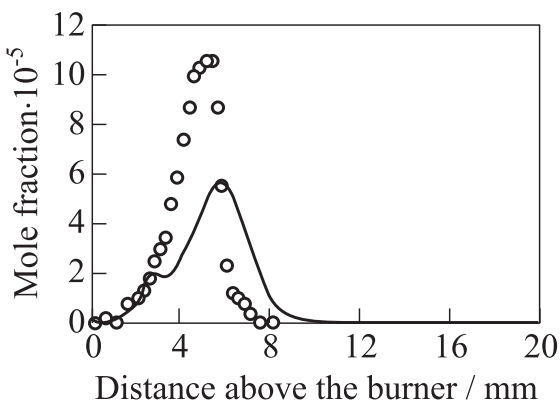

(c)

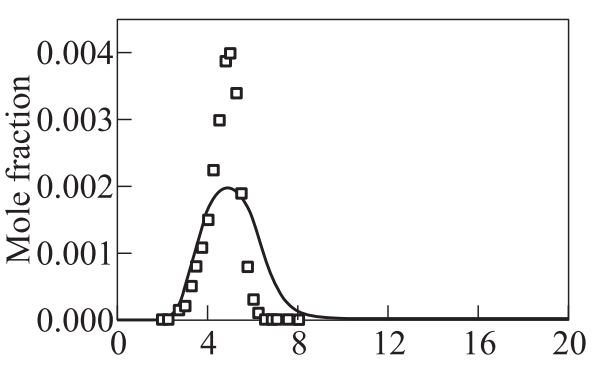

Distance above the burner / $\mathrm{mm}$

(b)

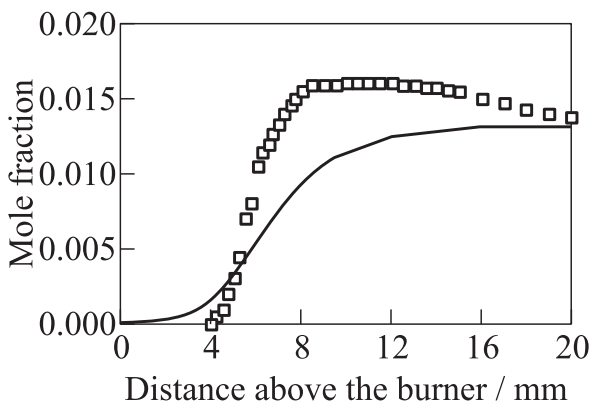

(d)

Figure 7 Comparison of modeled with current mechanisms (curves) $\mathrm{OH}(a), \mathrm{CH}_{3}(b)$, $\mathrm{HCO}(c)$, and $\mathrm{H}(d)$ concentration profiles with measured (signs) $\mathrm{CH}_{4} / \mathrm{O}_{2} / \mathrm{Ar}$ laminar premixed flame data [34], $p=0.05$ atm and $\phi=1.05$

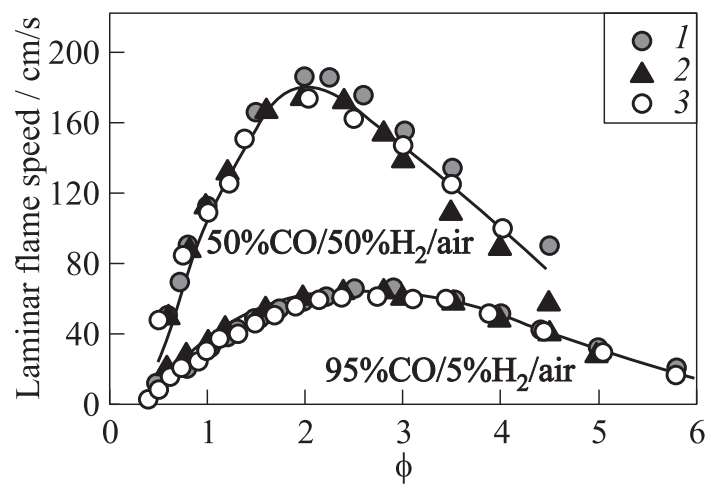

Figure 8 Comparison of modeled with current mechanisms (curves) laminar flame speed for $\mathrm{H}_{2} / \mathrm{CO} /$ air mixtures with experimental data (signs: $1-[40] ; 2-[39]$; and $3-[42]) ; p=1$ bar and $T_{0}=298 \mathrm{~K}$ 


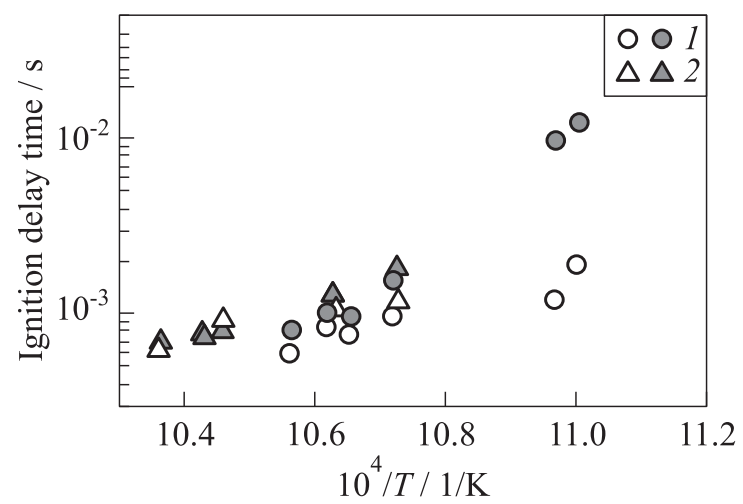

Figure 9 Comparison of modeled with current mechanisms (filled signs) ignition delays for $\mathrm{H}_{2} / \mathrm{CO} /$ air mixtures with shock tube experimental data [39] (empty signs): $1-p=1.2$ bar, $80 \% \mathrm{CO} / 20 \% \mathrm{H}_{2} / \mathrm{N}_{2}$; and $2-p=1.4$ bar, $90 \% \mathrm{CO} / 10 \% \mathrm{H}_{2} / \mathrm{Ar}$

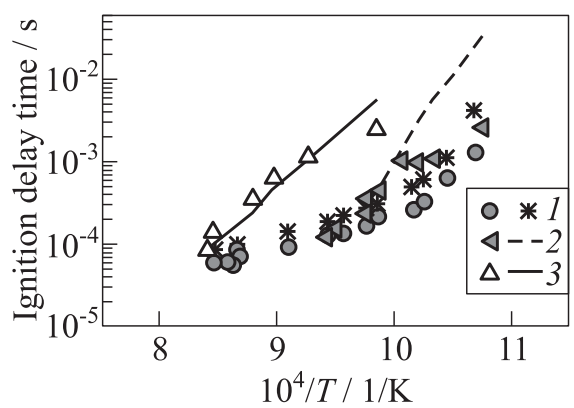

(a)

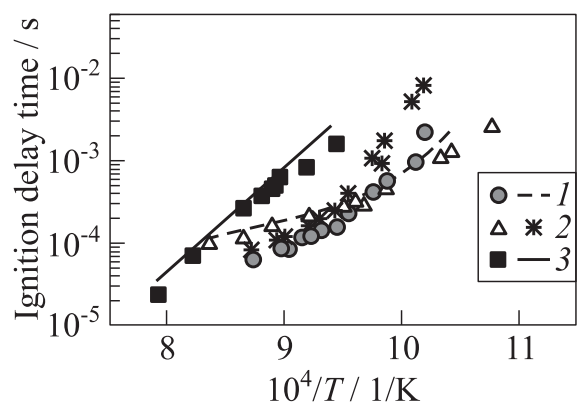

(b)

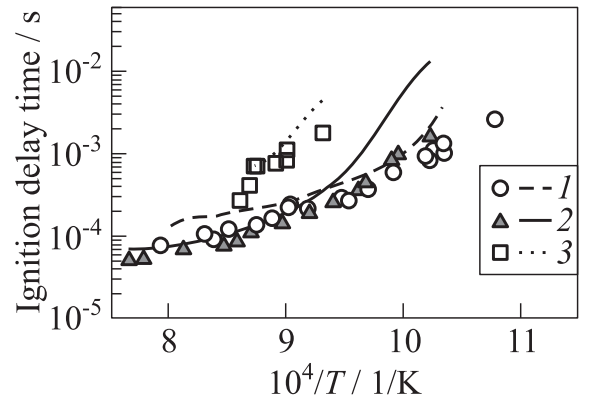

(c)

Figure 10 Comparison of modeled with current mechanisms (curves and stars) ignition delays for $\mathrm{H}_{2} / \mathrm{CO} /$ air mixtures with experimental data [38] (signs) at different pressures, $\phi=0.5: 1-p=1$ bar; $(a) 80 \% \mathrm{CO} / 20 \% \mathrm{H}_{2}, 2-p=2-3$ bar, and $3-$ $p=14-18$ bar; (b) $90 \% \mathrm{CO} / 10 \% \mathrm{H}_{2}, 2-p=2.5$ bar, and $3-p=13-17$ bar; and (c) $95 \% \mathrm{CO} / 5 \% \mathrm{H}_{2}, 2-p=2$ bar, and $3-p=13-15$ bar 


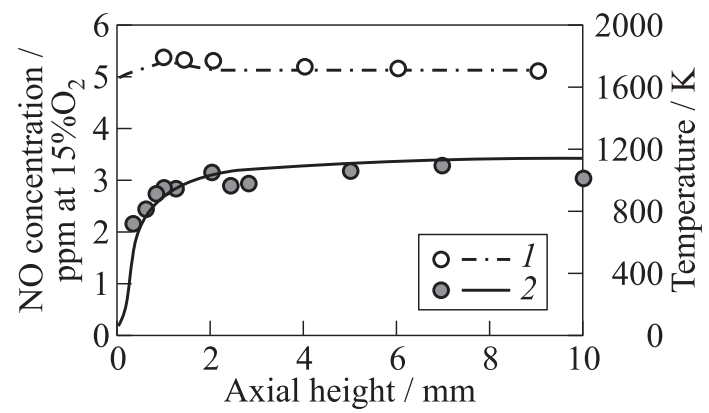

Figure 11 Comparison of modeled with current mechanisms (curves) temperature (1) and NO concentration profiles (2) with measured (signs) $\mathrm{CH}_{4} /$ air laminar premixed flame data [36], $p=1.0$ atm and $\phi=0.6$

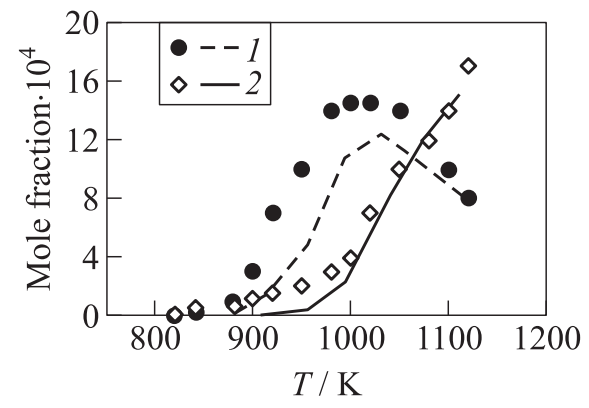

(a)

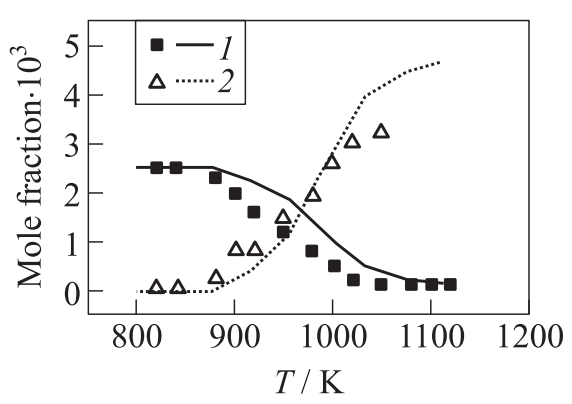

(b)

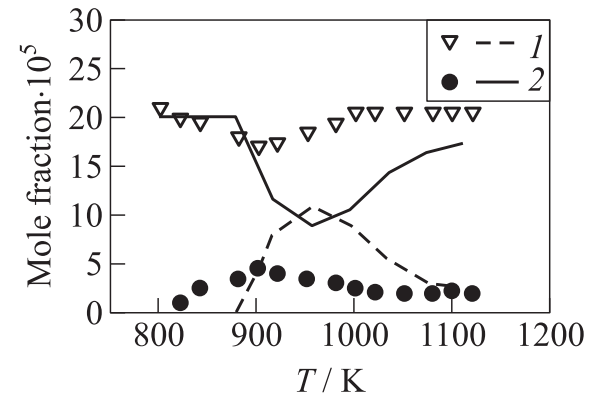

(c)

Figure 12 Comparison of modeled (curves) and measured in JSR (signs) concentration profiles for $\mathrm{CH}_{4} / \mathrm{O}_{2} / \mathrm{NO} / \mathrm{N}_{2}$ mixture [37], $p=1.0 \mathrm{~atm}, \phi=0.5$, and residence time 120 ms: (a) $1-\mathrm{CO}$ and $2-\mathrm{CO}_{2}$; (b) $1-\mathrm{CH}_{4}$ and $2-\mathrm{H}_{2} \mathrm{O}$; and $(c) 1-$ $\mathrm{NO}_{2}$ and $2-\mathrm{NO}$ 
presence of contaminants in the reactants or on experimental surfaces, compressible fluid dynamic effects, the inhomogeneous mixing, the catalysis from particles or surface materials in any combination can lead to reductions of the measured chemical induction time scales. Predictions of ignition delays with the homogeneous model that do not account for these perturbations can be significantly misleading. In addition, the possible differences in the ignition time definition can explain the deviations between simulations and experiments.

In Figs. 11 and 12, the comparison of calculated $\mathrm{NO}, \mathrm{NO}_{2}, \mathrm{CO}, \mathrm{CO}_{2}, \mathrm{CH}_{4}$ and $\mathrm{H}_{2} \mathrm{O}$ concentrations with the measured data $[36,37]$ in a burner stabilised laminar premixed flame and jet-stirred reactor (JSR) is shown. The obtained agreement is excellent for the NO concentration measured in the burner stabilised flame [36] (see Fig. 11).

The model reproduces trends in $\mathrm{NO}, \mathrm{NO}_{2}$ concentrations obtained in [37], but has an underprediction and an overprediction by the factor of 2 . Concentrations of $\mathrm{CO}, \mathrm{CO}_{2}, \mathrm{CH}_{4}$ and $\mathrm{H}_{2} \mathrm{O}$ [37] are well reproduced with the studied mechanism (see Fig. 12).

\section{PROBLEM FORMULATION}

The features and processes in a liquid propellant rocket engine are schematically shown in Fig. 13. The propellants enter either as dense supercritical gases or liquids. The first part of the combustion chamber is dominated by the atomization, mixing and combustion processes. The combustion gases are then accelerated in the nozzle up to hypersonic conditions and exhausted into the atmosphere. The presented investigation focuses on the evaluation of the amount of active radicals in the exhaust jet to evaluate a possible impact of rocket engines on the atmosphere, as these radicals can initiate chemical reactions with nitrogen and ozone in the environment. A special attention has been paid on reproducing the temperature and pressure distribution in the engine nozzle.

First, from the assumption of the thermodynamic equilibrium, the mixture temperature $T_{c}$, the enthalpy $\Delta H_{c}$ and the composition of a hot exhaust gas in the combustion chamber were calculated under the following conditions: the initial mixture temperature $T_{0}=180 \mathrm{~K}$; the pressure $p_{0}=100 \mathrm{~atm}$; the oxidizer/fuel $\left(\mathrm{O}_{2} / \mathrm{CH}_{4}\right)$ mass ratio $\phi=3.4$; the mass flow $g=700 \mathrm{~kg} / \mathrm{s}$; the initial gas velocity $v_{0}=300 \mathrm{~m} / \mathrm{s}$; and the radius of throat $r^{*}=25 \mathrm{~cm}$.

Second, the exit pressure $p_{\text {en }}$ was assumed equal to $0.2 \mathrm{~atm}$, what corresponds to the Mach number $\mathrm{M}=4.8$ for the ideal gas conditions. The area ratio from the throat $A^{*}$ to the exit $A_{\text {en }}$ was set from the exit Mach number.

The chemical processes in the studied convergent-divergent rocket nozzle were modeled with a chain of chemical reactors. As was already mentioned, 


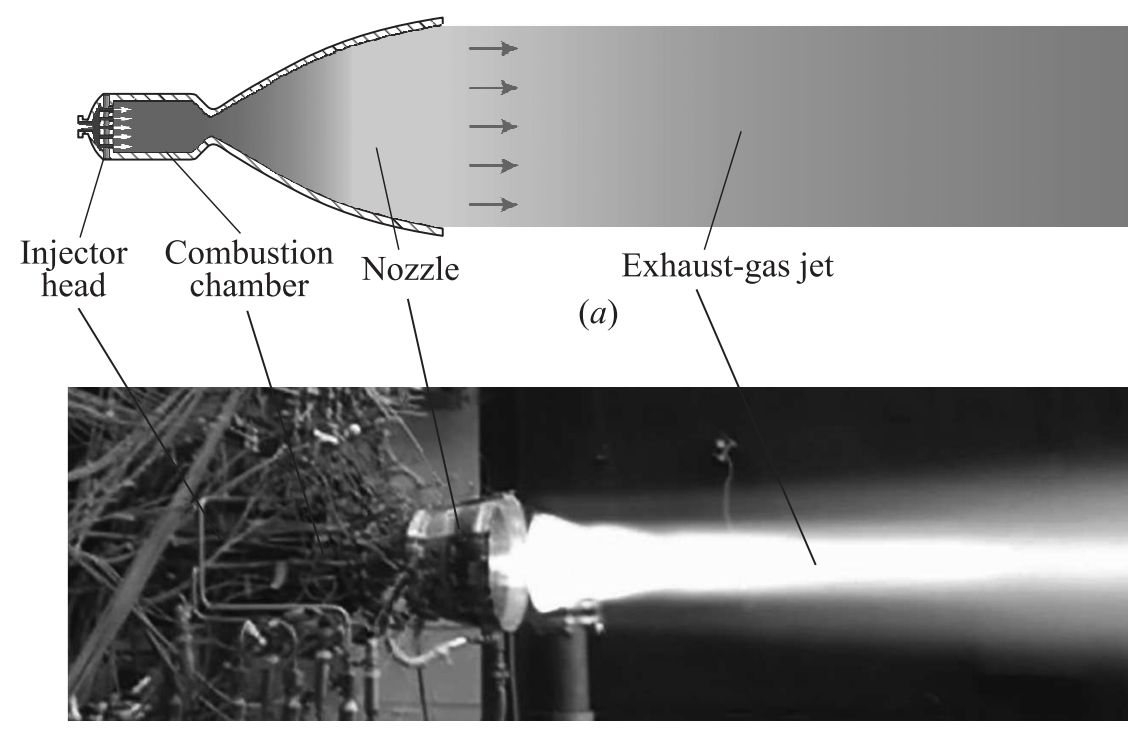

(b)

Figure 13 Model schematic for the multistage chemical processes in the rocket engines, including the interaction of the exhaust gas with the atmosphere $(a)$ and an image of the exhaust gas jet by the trust chamber test at European technology Test Facility P8 DLR Lampoldshausen (b)

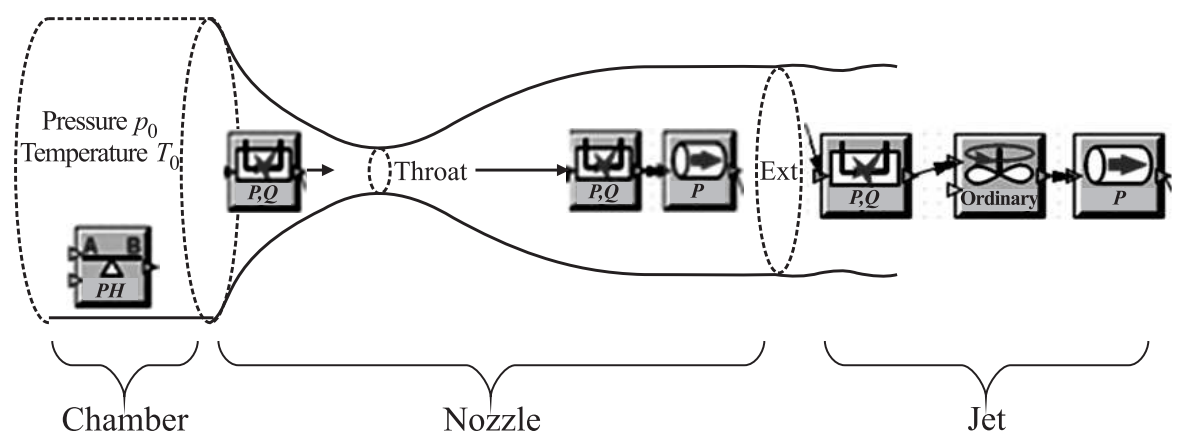

Figure 14 Schematic of the chemical reactors used to simulate chemical processes in the rocket engine 
the combustion chamber (Fig. 14) was modeled with an equilibrium reactor under the $p, H=$ const conditions. The convergent of the hot exhaust gas to the minimum area $A^{*}$, or throat, was simulated with a calorimetrical bomb reactor (CBR) of the preset pressure profile (pressure decrease from $p_{0}$ to the $p_{0}$ corresponding to $M=1$ ) (see Fig. 14). In the attached diverging section, downstream of the throat, the flow is isentropically expanded corresponding to a supersonic Mach number. The decrease of the static pressure and temperature accordingly to the variation of the cross section area $A$ of the trust chamber can be calculated as a function of the Mach number:

$$
\begin{aligned}
\frac{p}{p_{0}} & =\left(1+\frac{\gamma-1}{2} \mathrm{M}^{2}\right)^{-\gamma /(\gamma-1)} ; \\
\frac{T}{T_{0}} & =\left(1+\frac{\gamma-1}{2} \mathrm{M}^{2}\right)^{-1} ; \\
\left(\frac{A}{A^{*}}\right)^{2} & =\frac{1}{\mathrm{M}^{2}}\left[\frac{2}{\gamma+1}\left(1+\frac{\gamma-1}{2} \mathrm{M}^{2}\right)\right]^{(\gamma+1) /(\gamma-1)} .
\end{aligned}
$$

For rocket engines, the typical value of $\gamma$ is between 1.2 and 1.4. The aim of this study is to present the chemical kinetics occurring at $\gamma=1.4$ which, according to Eq. (6), delivers the lowest temperature limit on the nozzle outlet. These conditions are considered to be the most inappropriate for the chemical processes in the exhaust gases. In this way, one can objectively evaluate the possible impact of exhaust gases on the atmosphere under the given conditions. Nevertheless, it has a sufficient accuracy for the presented calculation.

To simulate the divergent section, six pairs of chemical reactors were used: $\mathrm{CBR}$ of the preset pressure profile to calculate thermodynamic parameters of

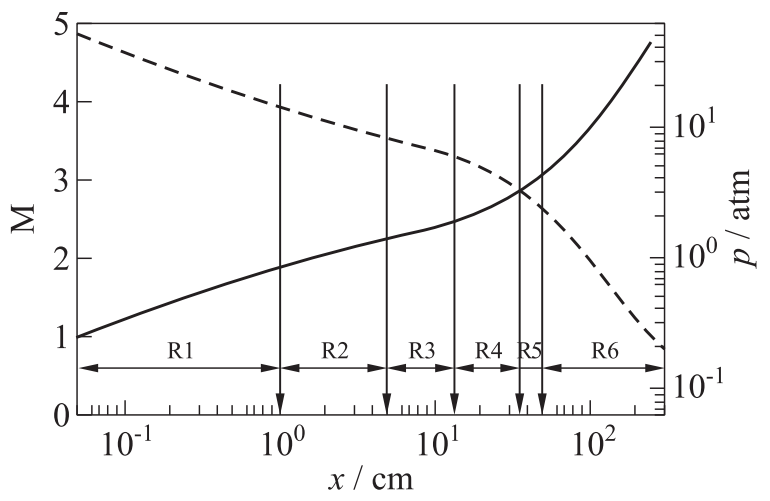

Figure 15 Evaluated Mach number and pressure profiles through the divergent rocket nozzle; R1, R2, R3, R4, R5 and R6 mark the six calculation zones in the nozzle 
the system under expansion and a plug flow reactor (PFR) under $p=$ const and preset heat loss conditions to reproduce the chemical processes at the "middle" pressure in each calculation zone. Altogether, $6 \mathrm{CBR} / \mathrm{PFR}$ couples were chosen to better fit the pressure and temperature profiles in the divergent section of the engine. The Mach number distribution and the pressure decrease in the nozzle together with the selected reactor division are demonstrated in Fig. 15. The heat loss in PFR reactors was calculated basing on the temperature decrease, Eq. (6), and the residence time in each reactor.

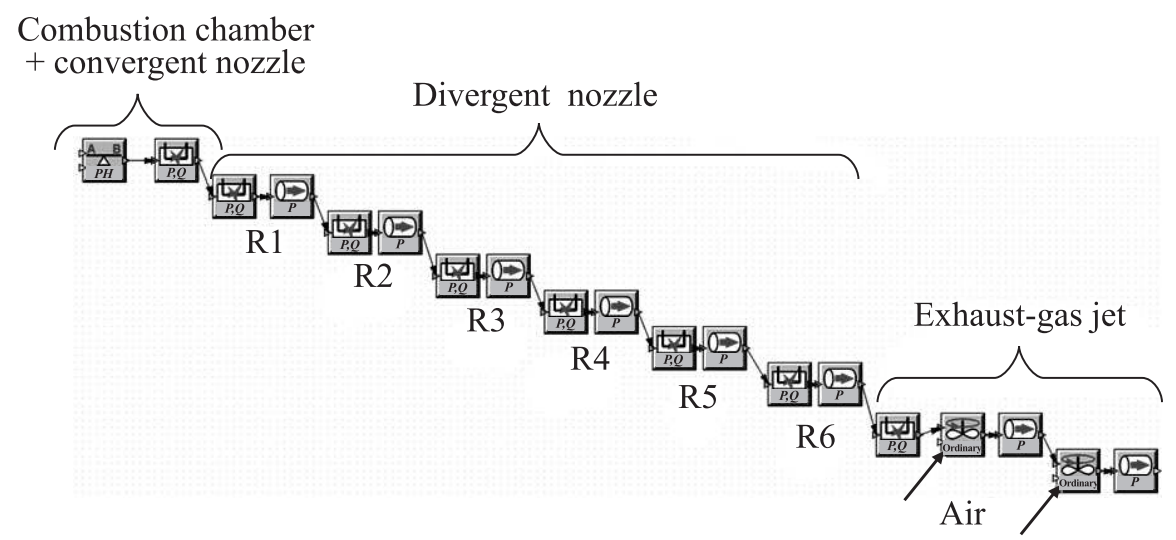

Figure 16 The reactor network chain used for the simulation of the chemical processes in rocket engine and exhaust-gas jet

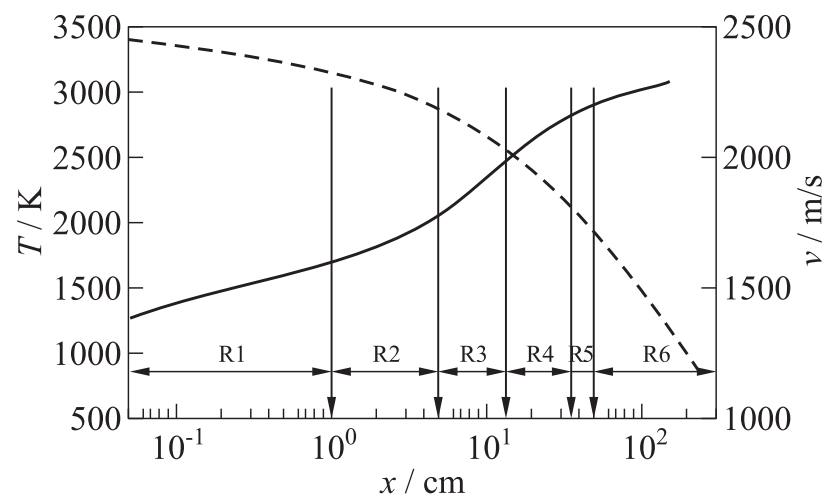

Figure 17 Calculated temperature and velocity profiles through the divergent rocket nozzle; R1, R2, R3, R4, R5 and R6 mark the six calculation zones in the nozzle 
To model the jet chemistry, first, the CBR of the preset pressure profile was used to calculate the exhaust-jet expansion to the atmospheric pressure, then a coupling of well stirred reactor (WSR) and PFR simulates the chemical interaction of the exhaust jet with air. Two such couples were used: the first describes the mixing with $5 \%$ of air (related to the exhaust mass flow) and chemical interactions on the length of $50 \mathrm{~m}$; and the second describes the chemical interaction down to the $100 \mathrm{~m}$ by mixing with the next $10 \%$ of air. The full reactor network is demonstrated in Fig. 16. The calculations were performed with CHEMICAL WORKBENCH [43] software.

In Fig. 17, the distribution of the simulated "middle" (for each modeled section) velocities and temperatures through the divergent nozzle and the selected reactor couples are shown.

\section{RESULTS AND DISCUSSION}

The chemical interaction of a high speed jet with the surrounding air was simulated for conditions related to the atmospheric altitude of 16 and $31 \mathrm{~km}$, i.e., for $p_{1}=0.01 \mathrm{~atm}$ and $T_{1}=228 \mathrm{~K}$ and $p_{2}=0.1 \mathrm{~atm}$ and $T_{2}=218 \mathrm{~K}$.

The exhaust-gas was gradually mixed with $5 \%$ of air (related to the exhaust mass flow) and then $10 \%$ of air in two WSRs (see Fig. 16).

The temperature decrease in the exhaust-jet is caused, first, by the flow extension (simulated with CBR) after the nozzle exit, and then, by the mixing with a cold air (simulated with WSR). The chemical reactions between exhaustgas and air do not influence the temperature in the exhaust, as it can be seen in Figs. 18-20: the obtained temperature decrease is caused mostly with thermodynamic processes in the jet. The temperature remains constant in PFRs. The calculated concentrations of the main combustion products are similar for two studied cases (see Fig. 18) and remain unchanged along the reactors. The concentration decrease in the second couple of reactors is caused by the recalculation of mole fractions after mixing with the second portion of air. In any case, the final concentrations of $\mathrm{CO}$ and $\mathrm{CO}_{2}$ in the exhaust are extremely high.

Main trends in radical concentrations (see Fig. 19) depend on the ambient conditions and are different for the two studied altitudes.

For the altitude of $31 \mathrm{~km}$ and $p_{1}=0.01 \mathrm{~atm}$ (see Fig. 19a), the concentrations of such radicals as $\mathrm{H}_{2} \mathrm{O}_{2}$ and $\mathrm{HO}_{2}$ increase downstream the flow, concentrations of $\mathrm{H}, \mathrm{HCO}$ and $\mathrm{CH}_{2} \mathrm{O}$ decrease, and concentrations of $\mathrm{O}$ and $\mathrm{OH}$, first, slightly increase and, then, decrease. The increase of $\mathrm{H}_{2} \mathrm{O}_{2}$ and $\mathrm{HO}_{2}$ concentrations can be explained with $\mathrm{H}_{2} / \mathrm{O}_{2}$ chemistry at the low temperature.

The radicals of $\mathrm{H}, \mathrm{O}, \mathrm{OH}, \mathrm{HCO}$, and $\mathrm{CH}_{2} \mathrm{O}$ will be slowly consumed (see Fig. $19 a$ ) through reactions with nitrogen compounds, when the air concentration 


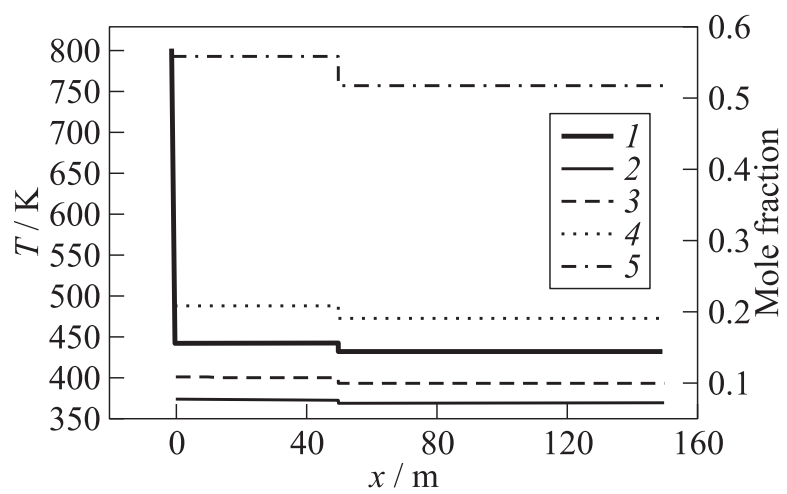

(a)

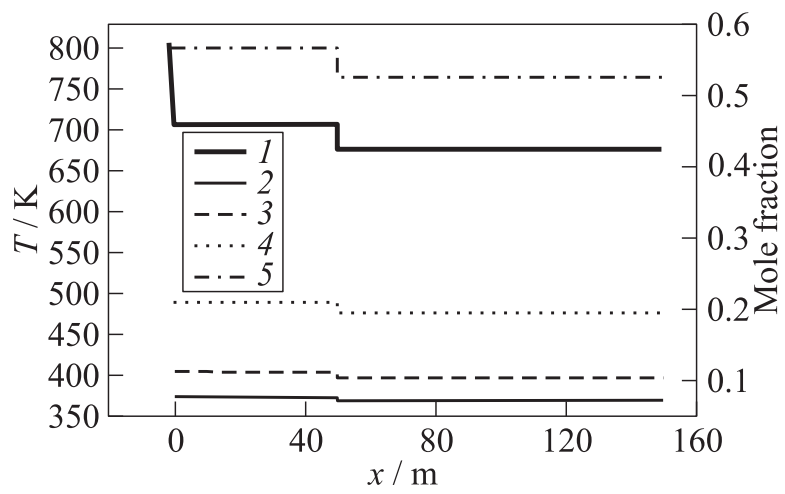

(b)

Figure 18 Temperature (1) and concentration profiles for the main products $(2-$ $\mathrm{H}_{2} ; 3-\mathrm{CO} ; 4-\mathrm{CO}_{2} ;$ and $\left.5-\mathrm{H}_{2} \mathrm{O}\right)$ calculated by gradually mixing $5 \%$ and $10 \%$ of air with the exhaust jet under ambient pressures: $(a) p_{1}=0.01 \mathrm{~atm}$; and (b) $p_{2}=0.1 \mathrm{~atm}$

in the exhaust jet increases (see Fig. 20a). As the main protective ozone layer is located on the altitude of $15-35 \mathrm{~km}$, the reactions of $\mathrm{O}_{3}$ with these radicals can be more preferable than the reactions with nitrogen compounds and have to be included in the model in the future.

On the altitude of $16 \mathrm{~km}$ and $p_{2}=0.1 \mathrm{~atm}$, the temperature in the jet is around $700 \mathrm{~K}$ after mixing. With the first portion of air, the small radicals $\mathrm{H}$, $\mathrm{O}, \mathrm{OH}$, and $\mathrm{HCO}$ are intensively consumed (see Fig. 19b) to produce nitrogen compounds, first of all $\mathrm{NO}_{2}$ (see Fig. 20b). With the temperature decrease due to the further cold air mixing, the reaction rates slow down and the concentration of these radicals do not change. The concentrations of heavy radicals $\mathrm{H}_{2} \mathrm{O}_{2}$, 


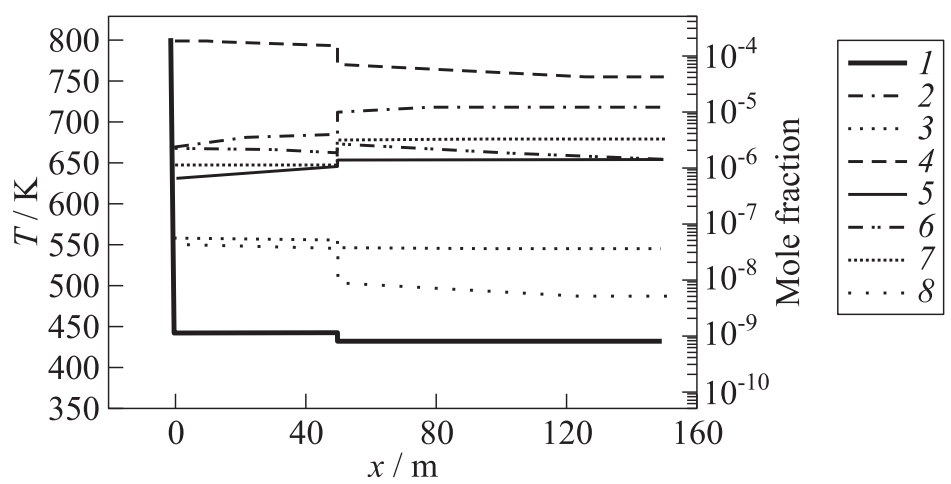

(a)

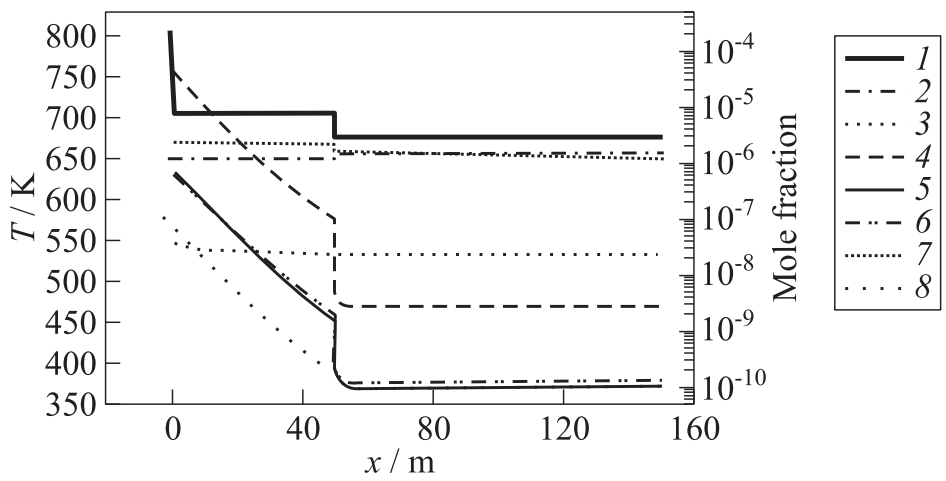

(b)

Figure 19 Temperature (1) and concentration profiles for main radicals $\left(2-\mathrm{H}_{2} \mathrm{O}_{2}\right.$; $3-\mathrm{CH}_{2} \mathrm{O} ; 4-\mathrm{H} ; 5-\mathrm{O} ; 6-\mathrm{OH} ; 7-\mathrm{HO}_{2}$; and $\left.8-\mathrm{HCO}\right)$ calculated by gradually mixing $5 \%$ and $10 \%$ of air with the exhaust jet under ambient pressures: (a) $p_{1}=0.01 \mathrm{~atm}$; and $(b) p_{2}=0.1 \mathrm{~atm}$

$\mathrm{HO}_{2}$, and $\mathrm{CH}_{2} \mathrm{O}$ basically do not change (see Fig. $19 b$ ) and have relatively high values. These radicals slowly react with nitrogen compounds, but can influence the $\mathrm{O}_{3}$ content in the atmosphere.

The performed simulations of nitrogen compounds (see Fig. 20) have shown that these compounds are produced in very small amounts at the studied conditions. Nevertheless, it is worth mentioning that, already at such low temperature, i. e., lower than $700 \mathrm{~K}$, the reaction of nitrogen compounds can start through the high concentrations of active radicals. A possible presence of ions, excited radicals, and molecules and high frequency ultraviolet light can sufficiently intensify reactions in the rocket exhaust jet. 


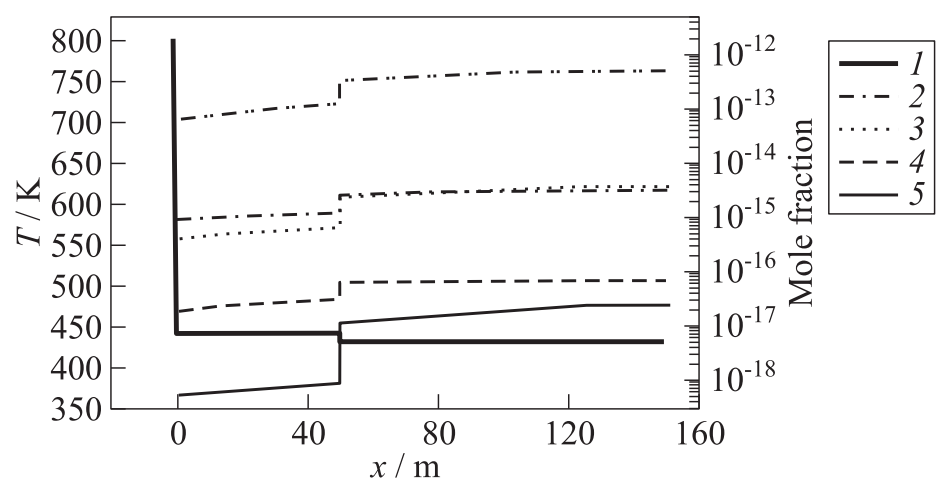

(a)

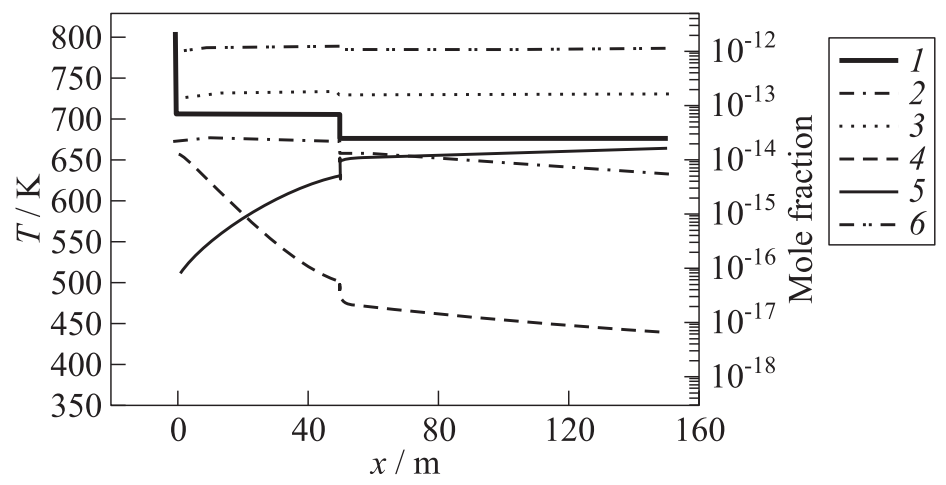

(b)

Figure 20 Temperature (1) and concentration profiles of nitrogen compounds (2 NO; $3-\mathrm{N}_{2} \mathrm{O} ; 4-\mathrm{NH}_{2} ; 5-\mathrm{NO}_{2}$; and $6-\mathrm{NH}_{3}$ ) calculated by gradually mixing $5 \%$ and $10 \%$ of air with the exhaust-jet under ambient pressures $(a) p_{1}=0.01 \mathrm{~atm}$; and $(b) p_{2}=0.1 \mathrm{~atm}:$

\section{CONCLUDING REMARKS AND OUTLOOK}

An earlier developed chemical kinetic model of the high-pressure methane combustion has been further developed for the low-pressure methane oxidation and augmented with the NOx submodel. The scheme is able to reflect the main properties of the methane combustion (including the production of nitrogen and its compounds) under the following operating conditions: $0.02<p<100 \mathrm{~atm}$, $300<T<1800 \mathrm{~K}$ and $0.5<\phi<3.0$.

The network of chemical reactors available in the CHEMICAL WORKBENCH [43] software has been successfully developed to simulate chem- 
ical processes in convergent-divergent rocket nozzle and in the exhaust jets. This network with the proposed reaction mechanism has been used to study the high-pressure/temperature processes in the rocket engine and low-pressure/ temperature reactions in the exhaust plume of a $\mathrm{CH}_{4} / \mathrm{LOx}$ rocket engine of a launch vehicle in the strato- and mesosphere.

These results clearly lead to the following conclusions:

- the exhaust gases of a methane/oxygen propelled liquid rocket engine contain high amounts of active radicals;

- the chemical reactions of these active radicals with the atmospheric environment at a pressure higher than $0.1 \mathrm{~atm}$ can provoke the formation of nitrogen compounds; and

- at a pressure lower than $0.01 \mathrm{~atm}$, the chemical reactions of exhaust active radicals with ozone become very important.

The performed simulations have demonstrated the necessity to investigate more carefully the chemical interaction of the exhaust jet with the environment by including the reaction of atmospheric chemistry in a reaction mechanism (radiation-activated reactions, reactions of ions and excited molecules, ozone reactions).

\section{ACKNOWLEDGMENTS}

Part of this work was performed within the "ISP-1" project, coordinated by SNECMA and supported by the European Union within the 7th Framework Program for Research \& Technology (grant agreement No. 218849). Many thanks to Dr. Eric L. Petersen and Dr. Timoty M. Ombrello for the sent experimental data and to Prof. Seth Dworkin for the useful discussion and the friendly help with the simulations.

\section{REFERENCES}

1. Stone, R., N. Tiliakos, V. Balepin, C.-Y. Tsai, and R. Engers. 2008. ALTITUDE testing of LOx-methane rocket engine at ATK-GASL. AIAA Paper No. 2008-3701.

2. Hurlbert, E., T. Angstadt, M. Villemarette, J. Collins, J. Allred, J. Mahoney, and T. Peters. 2008. $870 \mathrm{lbf}$ reaction control system tests using LOx/ethanol and LOx/methane at white sands test facility. AIAA Paper No. 2008-5247.

3. Kawashima, H., K. Okita, K. Aoki, N. Azuma, A. Kumakawa, T. Onodera, S. Yoshida, H. Negishi, H. Manako, and T. Koganezawa. 2009. Combustion and regenerative cooling characteristics of $\mathrm{LOx} /$ methane engine. Transactions of the 
Japan Society for Aeronautical and Space Sciences, Space Technology. Japan. 7(26):Ta_7-Ta_11. (ISTS Special Issue: Selected papers from the 26th Symposium (International) on Space Technology and Science.)

4. Arione, L. 2010. Development status of the LM10-MIRA engine for the LYRA launch vehicle. "Space 2010" Conference Proceedings. San Sebastian.

5. Smith, G. P., D. M. Golden, M. Frenklach, N. W. Moriarty, B. Eiteneer, M. Goldenberg, C. T. Bowman, R. K. Hanson, S. Song, W. C. Gardiner, Jr., V. V. Lissianski, and Z. Qin. http://www.me.berkeley.edu/gri_mech/.

6. Hughes, K. J., T. Turanyi, A. R. Clague, and M. J. Pilling. 2001. Development and testing of a comprehensive chemical mechanism for the oxidation of methane. Int. J. Chem. Kinet. 33:513-38.

7. Zsély, I. G., J. Zádor, and T. Turányi. 2005. Uncertainty analysis of updated hydrogen and carbon monoxide oxidation mechanisms. Proc. Combust. Inst. 30:1273-81.

8. Konnov, A. A. 2009. Implementation of the NCN pathway of prompt-NO formation in the detailed reaction mechanism. Combust. Flame 156:2093-105.

9. Petersen, E. L., D.F. Davidson, and R.K. Hanson. 1999. Ignition delay times of Ram accelerator $\mathrm{CH}_{4} / \mathrm{O}_{2} /$ diluent mixtures. J. Propul. Power 15:82-91.

10. Petersen, E. L., D.F. Davidson, and R.K. Hanson. 1999. Kinetics modeling of shock-induced ignition in low-dilution $\mathrm{CH}_{4} / \mathrm{O}_{2}$ mixtures at high pressures and intermediate temperatures. Combust. Flame 117:272-90.

11. Hall, J. M., and E. L. Petersen. 2005. Development of a chemical kinetics mechanism for $\mathrm{CH}_{4} / \mathrm{H}_{2}$ /air ignition at elevated pressures. AIAA Paper No. 2005-3768.

12. Li, S. C., and F. A. Williams. 1999. NOx formation in two-stage methane-air flames. Combust. Flame 118:399-414.

13. Li, S. C., and F. A. Williams. 2002. Reaction mechanisms for methane ignition. J. Eng. Gas Turbines Power 124:471-80.

14. Li, J., Z.W. Zhao, A. Kazakov, M. Chaos, F. L. Dryer, and J. J. Scire. 2007. A comprehensive kinetic mechanism for $\mathrm{CO}, \mathrm{CH}_{2} \mathrm{O}$ and $\mathrm{CH}_{3} \mathrm{OH}$ combustion. Int. J. Chem. Kinet. 39:109-36.

15. Le Cong, T., and P. Dagaut. 2007. Kinetics of natural gas, natural gas-syngas mixtures oxidation and effect of burnt gas recirculation: Experimental and detailed modeling. ASME Turbo Expo 2007 Proceedings: Power for Land, Sea and Air. GT2007-27146:1-9.

16. Le Cong, T., and P. Dagaut. 2008. Experimental and detailed kinetic modeling of the oxidation of methane and methane/syngas mixtures and effect of carbon dioxide addition. Combust. Sci. Technol. 180(10):2046-91.

17. Slavinskaya, N. A., and O. J. Haidn. 2008. Reduced chemical kinetic model mode for high pressure methane combustion with PAH formation. AIAA Paper No. 20081012 .

18. Slavinskaya, N. A., and P. Frank. 2009. A modeling study of aromatic soot precursors in laminar methane and ethene flames. Combust. Flame 156:1705-22.

19. Slavinskaya, N. A., A. Zizin, and U. Riedel. 2011. Towards surrogate reaction model development. ASME 2011. GT 2011-45198. 
20. Karach, S.P., and V.I. Osherov. 1999. Ab initio analysis of the transition states on the lowest triplet $\mathrm{H}_{2} \mathrm{O}_{2}$ potential surface. J. Chem. Phys. 110:11918-27.

21. Frassoldati, A., T. Faravelli, and E. Ranzi. 2007. The ignition, combustion and flame structure of carbon monoxide/hydrogen mixtures. Note 1: Detailed kinetic modeling of syngas combustion also in presence of nitrogen compounds. Int. J. Hydrogen Energy 32:3471-85.

22. Shatalov, O. P., L. B. Ibraguimova, V. A. Pavlov, G. D. Smekhov, and Yu. V. Tunik. 2009. Analysis of the kinetic data described oxygen-hydrogen mixtures combustion. 4th European Combustion Meeting. 222.

23. Isaacson, A.D. 1997. Harmonic and anharmonic rate constants and transmission coefficients obtained from ab initio data. J. Chem. Phys. 107:3831-39.

24. Konnov, A. 2008. Remaining uncertainties in the kinetic mechanism of hydrogen combustion. Combust. Flame 152:507-28.

25. Baulch, D. L., C. T. Bowman, C. J. Cobos, R. A. Cox, Th. Just, J. A. Kerr, M. J. Pilling, D. Stocker, J. Troe, W. Tsang, R. W. Walker, and J. Warnatz. 2005. Evaluated kinetic data for combustion modeling: Supplement II. J. Phys. Chem. Ref. Data 34(3):757-1397.

26. You, X., H. Wang, E. Goos, C. J. Sung, and S. J. Klippenstein. 2007. Reaction kinetics of $\mathrm{CO}+\mathrm{HO}_{2} \rightarrow$ products: $A b$ initio study and master equation modeling. J. Phys. Chem. A 111(19):4031-42.

27. Wooldridge, M. S., R.K. Hanson, and C. T. Bowman. 1996. A shock tube study of $\mathrm{CO}+\mathrm{OH}=\mathrm{CO}_{2}+\mathrm{H}$ and $\mathrm{HNCO}+\mathrm{OH}=$ Products via simultaneous laser absorption measurements of $\mathrm{OH}$ and $\mathrm{CO}_{2}$. Int. J. Chem. Kin. 28:361-72.

28. Kee, R. J., F. M. Rupley, and J. A. Miller. 1993. Chemkin-II: A FORTRAN chemical kinetics package for the analysis of gasphase chemical kinetics. Sandia Laboratories Report SAND89-8009B.

29. Hassan, M. I., K. T. Aung, and G. M. Faeth. 1998. Measured and predicted properties of laminar premixed methane/air flames at various pressures. Combust. Flame 115:539-50.

30. Seery, D. J., and C. T. Bowman. 1970. Ignition delays in several $\mathrm{CH}_{4}-\mathrm{O}_{2}-\mathrm{Ar}$ mixtures. Combust. Flame 14:37-47.

31. Petersen, E. L., D. M. Kalitan, and M. J. A. Rickard. 2004. Reflected shock ignition of $\mathrm{SiH}_{4} / \mathrm{H}_{2} / \mathrm{O}_{2} / \mathrm{Ar}$ and $\mathrm{SiH}_{4} / \mathrm{CH}_{4} / \mathrm{O}_{2} / \mathrm{Ar}$ mixtures. J. Propul. Power 20(4):66574 .

32. Petersen, E. L., J. M. Hall, S.D. Smith, J. de Vries, A.R. Amadio, and M. W. Crofton. 2007. Ignition of lean methane-based fuel blends at gas turbine pressures. J. Eng. Gas Turbines Power 129:937-44.

33. Berg, P. A., D. A. Hill, A. R. Noble, G. P. Smith, J. B. Jeffries, and D. R. Crosley. 2000. Absolute $\mathrm{CH}$ concentration measurements in low-pressure methane flames: Comparisons with model results. Combust. Flame 121:223-35.

34. Turbiez, A., A. El Bakali, J. F. Pauwels, A. Rida, and P. Meunier. 2004. Experimental study of a low pressure stoichiometric premixed methane, methane/ethane, methane/ethane/propane and synthetic natural gas flames. Fuel 83:933-41.

35. Ombrello, T. M., C.D. Carter, and V. Katta. 2011. Burner platform for subatmospheric pressure flame studies. AIAA Paper No. 2011-240. 
36. Thomsen, D. D., F.F. Kuligowski, and N. M. Laurendeau. 1999. Modeling of NO formation in premixed, high-pressure methane flames. Combust. Flame 119:307-18.

37. Dagaut, P., and A. Nicolle. 2005. Experimental study and detailed kinetic modeling of the effect of exhaust gas on fuel combustion: mutual sensitization of the oxidation of nitric oxide and methane over extended temperature andpressure ranges. Combust. Flame 140:161-71.

38. Kalitan, D. M., J. D. Mertens, M. W. Crofton, and E. L. Petersen. 2007. Ignition and oxidation of lean $\mathrm{CO} / \mathrm{H}_{2}$ fuel blends in air. J. Propul. Power 23:1291-303.

39. Mertens, J.D. 2009. Determination of the rate of $\mathrm{H}+\mathrm{O}_{2}+M \rightarrow \mathrm{HO}_{2}+M(M$ $\left.=\mathrm{N}_{2}, \mathrm{Ar}, \mathrm{H}_{2} \mathrm{O}\right)$ from ignition of syngas at practical conditions. Proc. Combust. Inst. 32:295-303.

40. McLean, I. C., D. B. Smith, and S. C. Taylor. 1994. The use of carbon monoxide/hydrogen burning velocities to examine the rate of the $\mathrm{CO}+\mathrm{OH}$ reaction. Proc. Combust. Inst. 25:749-57.

41. Hassan, M. I., K. T. Aung, and G. M. Faeth. 1997. Properties of laminar premixed $\mathrm{CO} / \mathrm{H}_{2} / \mathrm{Ar}$ flames at various pressures. J. Propul. Power 13(2):239-45.

42. Sun, H., S. I. Yang, G. Jomaas, and C. K. Law. 2007. High-pressure laminar flame speeds and kinetic modeling of carbon monoxide/hydrogen combustion. Proc. Combust. Inst. 31:439-46.

43. http://www.kintechlab.com/products/chemical-workbench/. 